\title{
Article \\ Genetic Variants of lncRNA GAS5 Are Associated with the Clinicopathologic Development of Oral Cancer
}

\author{
Ming-Hong Hsieh ${ }^{1,2}{ }^{\mathbb{D}}$, Hsueh-Ju Lu ${ }^{1,3}$, Chiao-Wen Lin ${ }^{4,5}$, Chia-Yi Lee ${ }^{6}{ }^{\mathbb{D}}$, Shang-Jung Yang ${ }^{7,8}$, Pei-Hsuan Wu ${ }^{9}$, \\ Mu-Kuan Chen $1,10, *$ and Shun-Fa Yang $11,12, *$ (D)
}

1 School of Medicine, Chung Shan Medical University, Taichung 402, Taiwan; mhhpsy@hotmail.com (M.-H.H.); hsuehju0311@gmail.com (H.-J.L.)

2 Department of Psychiatry, Chung Shan Medical University Hospital, Taichung 402, Taiwan

3 Division of Hematology and Oncology, Department of Internal Medicine, Chung Shan Medical University Hospital, Taichung 402, Taiwan

4 Institute of Oral Sciences, Chung Shan Medical University, Taichung 402, Taiwan; cwlin@csmu.edu.tw

5 Department of Dentistry, Chung Shan Medical University Hospital, Taichung 402, Taiwan

6 Department of Ophthalmology, Show Chwan Memorial Hospital, Changhua 500, Taiwan; ao6u.3msn@hotmail.com

7 Department of Radiology, Shuang-Ho Hospital, Taipei Medical University and School of Medicine, Zhonghe 235, Taiwan; abyss1989@hotmail.com

8 College of Medicine, Taipei Medical University, Taipei 110, Taiwan

9 Department of Otolaryngology-Head and Neck Surgery, Tri-Service General Hospital, Taipei 114, Taiwan; paulownia497@gmail.com

10 Department of Otorhinolaryngology-Head and Neck Surgery, Changhua Christian Hospital, Changhua 500, Taiwan

11 Institute of Medicine, Chung Shan Medical University, Taichung 402, Taiwan

check for

updates

Citation: Hsieh, M.-H.; Lu, H.-J.; Lin, C.-W.; Lee, C.-Y.; Yang, S.-J.; Wu, P.-H.; Chen, M.-K.; Yang, S.-F. Genetic Variants of lncRNA GAS5 Are Associated with the Clinicopathologic Development of Oral Cancer. J. Pers. Med. 2021, 11, 348. https://doi.org/ $10.3390 /$ jpm 11050348

Academic Editor: Su-Jun Lee

Received: 23 March 2021

Accepted: 23 April 2021

Published: 26 April 2021

Publisher's Note: MDPI stays neutral with regard to jurisdictional claims in published maps and institutional affiliations.

Copyright: (C) 2021 by the authors Licensee MDPI, Basel, Switzerland. This article is an open access article distributed under the terms and conditions of the Creative Commons Attribution (CC BY) license (https:/ / creativecommons.org/licenses/by/ $4.0 /)$.
12 Department of Medical Research, Chung Shan Medical University Hospital, Taichung 402, Taiwan

* Correspondence: 53780@cch.org.tw (M.-K.C.); ysf@csmu.edu.tw (S.-F.Y.)

Abstract: The long noncoding RNA, Growth arrest-specific 5 (GAS5) plays a crucial role in the development of oral cancer. However, potential genetic variants in GAS5 that affect the susceptibility and progression of oral cancer have rarely been explored. In this study, two loci of GAS5 single nucleotide polymorphisms (SNPs) (rs145204276 and rs55829688) were genotyped by using the TaqMan allelic discrimination in 1125 oral cancer patients and 1195 non-oral-cancer individuals. After statistical analyses, the distribution of both the GAS5 SNP rs145204276 and GAS5 SNP rs55829688 frequencies were similar between the study and control groups. However, the patients with GAS5 SNP rs145204276 variants (Ins/Del or Del/Del) showed a higher tendency of moderate to poor cell differentiation of oral cancer (OR: 1.454, 95\% CI: 1.041-2.031, $p=0.028$ ). Moreover, the GAS5 SNP rs145204276 variants (Ins/Del or Del/Del) in the non-alcohol-drinking population were associated with significantly advanced tumor stage (OR: 1.500, 95\% CI: 1.081-2.081, $p=0.015$ ) and larger tumor size (OR: 1.494, 95\% CI: 1.076-2.074, $p=0.016$ ). Furthermore, individuals with the GAS5 SNP rs145204276 variant were associated with a higher expression of GAS5 in the GTEx database $(p=0.002)$, and the higher GAS5 level was associated with poor cell differentiation, advanced tumor stage and larger tumor size in head and neck squamous cell carcinoma from the TCGA database (all $p<0.05$ ). In conclusion, the GAS5 SNP rs145204276 variant is related to poor-differentiation cell status in oral cancer. Besides, the presence of the GAS5 SNP rs145204276 variant is associated with a worse tumor stage and tumor size in oral cancer patients without alcohol drinking.

Keywords: growth arrest-specific 5; single nucleotide polymorphism; oral cancer; cell differentiation; tumor stage

\section{Introduction}

Oral cancer is one of the most prevalent malignancies throughout the world and leads to significant problems for public health $[1,2]$. In a previous epidemiological survey, 
the annual new cases of oral cancer were above 400 thousand worldwide, and a higher incidence was found in western countries and a Southern-Eastern Asia population [3]. The known risk factors for oral cancer include betel nut chewing, alcohol consumption and cigarette smoking [3-6], and the male-to-female ratio of oral cancer development was estimated as 5.62:1 in Taiwan [7]. The current treatment of oral cancer combines surgical excision, radiotherapy and chemotherapy [1], with five-year survival rates of about 40 to 60 percent [8-10]. Recently, the role of target therapy targeting cancer cell markers is under investigation [11].

Similar to other types of cancers, the environment as well as genetic factors will influence the clinical presentation and disease severity of oral cancer [12-16]. For instance, the insulin-like growth factor 2 mRNA-binding protein 2, a protein that contributes to insulin resistance and lipid metabolism, was related to less favorable clinical characters for oral cancer [17]. Additionally, the genetic polymorphism of chemokine receptor-2 gene enhances the susceptibility of oral cancer development [18]. In a survey on the gene other than protein, an early study showed that the single nucleotide polymorphism (SNP) of HOX transcript antisense intergenic RNA (HOTAIR) led to large-size tumors and an elevated risk of lymph node metastasis in non-betel quid chewers [19], implying the relationship between oral cancer and RNA polymorphism.

The Growth arrest-specific 5 (GAS5) is a long non-coding RNA that obtained the name due to the overexpression of itself in the growth-arrested cells $[20,21]$. Due to the ability of GAS5 to induce apoptosis and suppress tumor growth, the relationship between GAS5 and a wide range of malignancies was evaluated [21,22]. The overexpression of GAS5 can inhibit the proliferation of gastric cancer cells, [23] and a higher GAS5 level may cause the retardation of tumor angiogenesis [24]. On the other hand, the genetic polymorphism of GAS5 can lead to different effects on tumorigenesis; the SNP rs145204276 del/del genotype of GAS5 was associated with higher susceptibility of glioma [25]. Since the expression of GAS5 and its SNP influences the clinical characters in many neoplasms, it may also affect the clinical course of oral cancer for each gender, but this has rarely been evaluated in detail.

The purpose of the current study is to evaluate whether the distribution of GAS5 SNP will affect the clinicopathological characters of oral cancer in a male population. In addition, the distribution of GAS5 SNP between patients with oral cancer and non-oralcancer individuals was also analyzed.

\section{Materials and Methods}

\subsection{Subject Selection}

A prospective case-control study was conducted in both the Changhua Christian Hospital and Chung Shan Medical University Hospital, Taichung, Taiwan. Subjects who were (1) diagnosed with oral cancers, (2) of male gender and (3) were followed up with for at least six months in the Changhua Christian Hospital or the Chung Shan Medical University Hospital were recruited as the study group. After the selection, a total of 1125 men with oral cancer were included. For comparison, 1195 gender-matched, cancerfree controls were randomly selected from the Taiwan Biobank Project. The medical charts of these patients were examined, and the demographic data including the age, betel quid chewing condition, cigarette smoking status and alcohol drinking status of each subject were obtained. To analyze the genetic polymorphism of GAS5, venous blood drawing was performed for all patients in the Changhua Christian Hospital and Chung Shan Medical University Hospital, and the venous blood samples were preserved in ethylenediaminetetraacetic acid-containing tubes. After the reservation of venous blood samples, each sample was immediately centrifuged and stored in the laboratory refrigerator at approximately -80 degrees Celsius for the analyses. Peripheral blood was collected from each participant after informed consent. The research design was approved by the Institutional Review Board of the Chung Shan Medical University Hospital (CSMUH No: CS15125). 


\subsection{Genomic Extraction and Determination of GAS5 SNP via Real-Time PCR}

Two SNPs of GAS5, meaning the rs145204276 (Ins/Del) and the rs55829688 (T/C), were chosen since their minor allele frequencies were more than 5 percent, and earlier studies indicated their influence in other cancers $[26,27]$. The genotyping procedure used in the current study was similar as a previous study [28]; the genome was firstly extracted from the leukocytes in the venous blood from each participant via the QIAamp DNA kits (Qiagen, Valencia, Valencia, CA, USA) according to the manufacturer's instruction for DNA isolation $[29,30]$. Then, the isolated DNA was stored at -20 degrees Celsius. After that, the genetic polymorphism concerning both the GAS5 SNPs rs145204276 and the rs55829688 (T/C) were evaluated via the application of the ABI StepOne Real-Time PCR System (Applied Biosystems, Foster City, CA, USA). Then, the results of the GAS5 polymorphisms were analyzed by SDS version 3.0 software (Applied Biosystems, Foster City, CA, USA).

\subsection{Bioinformatics Analysis}

To illustrate the relationship between rs145204276 SNP and GAS5 expression, the data from the Genotype-Tissue Expression (GTEx) database were applied to reveal the correlations between rs145204276 SNP and GAS5 expression in esophagus mucosa tissues [31]. Moreover, the correlation between GAS5 expression and the clinical presentations of oral cancers (head and neck squamous cell carcinoma) was demonstrated according to the dataset of The Cancer Genome Atlas (TCGA) [32].

\subsection{Statistical Analysis}

SAS version 9.4 (SAS Institute Inc., Cary, NC, USA) was applied for the statistical analyses in the current study. Descriptive analysis by mean, standard deviation (SD) or percentage was used to show the demographic data between the oral cancer patients and non-oral-cancer individuals. Additionally, the tumor stage, including the tumor, node, metastasis (TNM) status and tumor cell differentiation in the study group, was expressed via descriptive analysis. Then, the Mann-Whitney U test was used to compare the differences in demographic data between the study and control groups. After that, logistic regression was applied to calculate the odds ratio (OR) of the GAS5 SNP distribution between the study and control groups, while multiple logistic regression was used to yield the adjusted odds ratios (AOR) with correlated $95 \%$ confidence intervals (CI) for the two GAS5 SNPs distribution between the study and control groups, after adjusting for betel nut chewing, alcohol use and tobacco consumption. In addition, the influence of the GAS5 SNPs frequency on the clinicopathological characteristics of oral cancer was evaluated via logistic regression again for the whole study group, and a subgroup analysis of the oral cancer patients without alcohol use history was conducted with the same method. A $p$ value that is less than 0.05 was regarded as statistically significance.

\section{Results}

\subsection{Basic Characters between the Oral Cancer and Non-Oral Cancer Individuals}

The mean age was $55.28 \pm 10.98$ years old in the study group and $53.91 \pm 10.01$ years old in the control group without a significant difference $(p=0.667)$ (Table 1). On the other hand, the study group showed higher ratios of betel nut chewing (73.9\% versus $16.6 \%$ ), cigarette smoking ( $84.7 \%$ versus $53.1 \%$ ) and alcohol drinking (46.8\% versus $19.8 \%$ ) compared to the control group with statistical significance (all $p<0.001$ ) (Table 1). The details of cancer subtype and clinical characters of oral cancer in the study group are shown in Table 1.

\subsection{Distribution of GAS5 SNP Frequencies between the Study and Control Groups}

Regarding GAS5 SNP rs145204276, 59.1\% and 58.7\% patients in the study and control groups, respectively, expressed the rs145204276 Ins/Del or Del/Del genotypes, and the distribution of GAS5 SNP rs145204276 frequencies was similar between the study and control groups with similar AOR (Table 2). Besides, the GAS5 SNP rs55829688 TC + CC genotype 
was found in $51.9 \%$ and $50.2 \%$ of patients in the study and control groups, respectively. The distribution of GAS5 SNP rs55829688 frequencies also showed no significant difference between the two groups concerning the AOR (Table 2).

Table 1. The distributions of demographical characteristics in 1195 controls and 1125 male patients with oral cancer.

\begin{tabular}{|c|c|c|c|}
\hline Variables & Controls $(n=1195)$ & Patients ( $n=1125$ ) & $p$ Value \\
\hline Age (yrs) & $53.91 \pm 10.01$ & $55.28 \pm 10.98$ & \\
\hline$<55$ & $564(47.2 \%)$ & $541(48.1 \%)$ & $p=0.667$ \\
\hline$\geq 55$ & $631(52.8 \%)$ & $584(51.9 \%)$ & \\
\hline \multicolumn{4}{|l|}{ Betel nut chewing } \\
\hline No & $997(83.4 \%)$ & $294(26.1 \%)$ & \\
\hline Yes & $198(16.6 \%)$ & $831(73.9 \%)$ & $p<0.001 *$ \\
\hline \multicolumn{4}{|l|}{ Cigarette smoking } \\
\hline No & $560(46.9 \%)$ & $172(15.3 \%)$ & \\
\hline Yes & $635(53.1 \%)$ & $953(84.7 \%)$ & $p<0.001 *$ \\
\hline \multicolumn{4}{|l|}{ Alcohol drinking } \\
\hline No & $958(80.2 \%)$ & $598(53.2 \%)$ & \\
\hline Yes & $237(19.8 \%)$ & $527(46.8 \%)$ & $p<0.001^{*}$ \\
\hline \multicolumn{4}{|l|}{ Cancer location } \\
\hline Buccal mucosa & & $398(35.4 \%)$ & \\
\hline Tongue & & $356(31.6 \%)$ & \\
\hline Gingiva & & $111(9.9 \%)$ & \\
\hline Lip & & $57(5.1 \%)$ & \\
\hline Others & & $203(18.0 \%)$ & \\
\hline \multicolumn{4}{|l|}{ Stage } \\
\hline $\mathrm{I}+\mathrm{II}$ & & $529(47.0 \%)$ & \\
\hline $\mathrm{III}+\mathrm{IV}$ & & $596(53.0 \%)$ & \\
\hline \multicolumn{4}{|l|}{ Tumor T status } \\
\hline $\mathrm{T} 1+\mathrm{T} 2$ & & $582(51.7 \%)$ & \\
\hline $\mathrm{T} 3+\mathrm{T} 4$ & & $543(48.3 \%)$ & \\
\hline \multicolumn{4}{|l|}{ Lymph node status } \\
\hline N0 & & $745(66.2 \%)$ & \\
\hline $\mathrm{N} 1+\mathrm{N} 2+\mathrm{N} 3$ & & $380(33.8 \%)$ & \\
\hline \multicolumn{4}{|l|}{ Metastasis } \\
\hline M0 & & $1114(99.0 \%)$ & \\
\hline M1 & & $11(1.0 \%)$ & \\
\hline \multicolumn{4}{|l|}{ Cell differentiation } \\
\hline Well differentiated & & $162(14.4 \%)$ & \\
\hline $\begin{array}{l}\text { Moderately or poorly } \\
\text { differentiated }\end{array}$ & & $963(85.6 \%)$ & \\
\hline
\end{tabular}

\subsection{Distribution Frequency of GAS5 SNP rs145204276 and the Clinicopathological Characteristics of Oral Cancers}

Concerning the clinicopathological characteristics of oral cancers with different genotypes of GAS5 SNP rs145204276, the patients with GAS5 SNP rs145204276 variants (Ins/Del or Del/Del) showed a higher tendency of moderate to poor cell differentiation of oral cancer (OR: 1.454, 95\% CI: 1.041-2.031, $p=0.028$ ). Nevertheless, the genotypes of GAS5 SNP rs145204276 did not influence the status of clinical stage, tumor size, lymph node invasion or distal metastasis (all $p>0.05$ ) (Table 3). Moreover, the genotypes of GAS5 SNP rs55829688 did not influence the clinicopathological characteristics of oral cancer (data not shown). In the subgroup analysis that only enrolled the oral cancer patients without alcohol drinking, the GAS5 SNP rs145204276 variants (Ins/Del or Del/Del) in this population were associated with significantly advanced tumor stage (OR: 1.500, 95\% CI: 1.081-2.081, $p=0.015)$ and larger tumor size (OR: $1.494,95 \%$ CI: 1.076-2.074, $p=0.016)$. The other clinicopathological characteristics of oral cancer, including lymph node invasion, distal 
metastasis and cell differentiation, did not relate to the presence of GAS5 SNP rs145204276 variants (all $p>0.05)$ (Table 4).

Table 2. Odds ratio (OR) and 95\% confidence interval (CI) of oral cancer associated with GAS5 genotypic frequencies.

\begin{tabular}{|c|c|c|c|c|}
\hline Variables & Controls $(n=1195) \mathrm{N}(\%)$ & Patients $(n=1125) \mathrm{N}(\%)$ & OR $(95 \% \mathrm{CI})$ & AOR $(95 \% \mathrm{CI})$ \\
\hline \multicolumn{5}{|l|}{ rs145204276 } \\
\hline Ins/Ins & $493(41.3 \%)$ & $460(40.9 \%)$ & 1.000 (reference) & 1.000 (reference) \\
\hline Ins/Del & $543(45.4 \%)$ & $526(46.8 \%)$ & $1.038(0.872-1.236)$ & $1.073(0.866-1.331)$ \\
\hline Del/Del & $159(13.3 \%)$ & $139(12.3 \%)$ & $0.937(0.722-1.216)$ & $0.986(0.716-1.358)$ \\
\hline Ins/Del + Del/Del & $702(58.7 \%)$ & $665(59.1 \%)$ & $1.015(0.860-1.198)$ & $1.054(0.859-1.292)$ \\
\hline \multicolumn{5}{|l|}{ rs55829688 } \\
\hline $\mathrm{TT}$ & $595(49.8 \%)$ & $541(48.1 \%)$ & 1.000 (reference) & 1.000 (reference) \\
\hline $\mathrm{TC}$ & $473(39.6 \%)$ & $470(41.8 \%)$ & $1.093(0.919-1.299)$ & $1.077(0.870-1.332)$ \\
\hline $\mathrm{CC}$ & $127(10.6 \%)$ & $114(10.1 \%)$ & $0.987(0.747-1.304)$ & $1.022(0.726-1.440)$ \\
\hline $\mathrm{TC}+\mathrm{CC}$ & $600(50.2 \%)$ & $584(51.9 \%)$ & $1.070(0.910-1.260)$ & $1.065(0.872-1.302)$ \\
\hline
\end{tabular}

$\mathrm{N}$ : number. OR: odds ratio. AOR: adjusted odds ratio.

Table 3. Clinical statuses and GAS5 rs145204276 genotype frequencies in oral cancer.

\begin{tabular}{|c|c|c|c|c|}
\hline \multirow[b]{2}{*}{ Variables } & \multicolumn{4}{|c|}{ GAS5 (rs145204276) } \\
\hline & Ins/Ins (\%) $(n=460)$ & $\begin{array}{l}\text { Ins/Del + Del/Del } \\
(\%)(n=665)\end{array}$ & OR $(95 \%$ CI $)$ & $p$ Value \\
\hline \multicolumn{5}{|l|}{ Clinical Stage } \\
\hline Stage I/II & $231(50.2 \%)$ & $298(44.8 \%)$ & 1.00 & $p=0.074$ \\
\hline Stage III/IV & $229(49.8 \%)$ & $367(55.2 \%)$ & $1.242(0.979-1.577)$ & \\
\hline \multicolumn{5}{|l|}{ Tumor size } \\
\hline$\leq \mathrm{T} 2$ & $245(53.3 \%)$ & 337 (50.7\%) & 1.00 & $p=0.394$ \\
\hline$>\mathrm{T} 2$ & $215(46.7 \%)$ & $328(49.3 \%)$ & $1.109(0.874-1.407)$ & \\
\hline \multicolumn{5}{|l|}{$\begin{array}{l}\text { Lymph node } \\
\text { metastasis }\end{array}$} \\
\hline No & $310(67.4 \%)$ & $435(65.4 \%)$ & 1.00 & $p=0.490$ \\
\hline Yes & $150(32.6 \%)$ & $230(34.6 \%)$ & $1.093(0.849-1.406)$ & \\
\hline \multicolumn{5}{|l|}{ Distant metastasis } \\
\hline No & $453(98.5 \%)$ & $661(99.4 \%)$ & 1.00 & $p=0.123$ \\
\hline Yes & $7(1.5 \%)$ & $4(0.6 \%)$ & $0.392(0.114-1.346)$ & \\
\hline \multicolumn{5}{|l|}{ Cell differentiation } \\
\hline well & $79(17.2 \%)$ & $83(12.5 \%)$ & 1.00 & $p=0.028$ * \\
\hline Moderate/poor & $381(82.8 \%)$ & $582(87.5 \%)$ & $1.454(1.041-2.031)$ & \\
\hline
\end{tabular}

* denotes significant difference of clinicopathological characteristics between the different GAS5 rs145204276 genotypes.

3.4. Relationship among GAS5 rs145204276, GAS5 Expression and Clinical Characters of Head and Neck Cancers from Worldwide Database

To strengthen our findings and hypotheses further by incorporating other real-world experiences, the data from the GTEx were obtained and analyzed in the current study. The results showed that individuals with the GAS5 SNP rs145204276 variant Ins/Del $(n=75)$ or $\mathrm{Del} / \mathrm{Del}(n=4)$ were associated with a higher expression of GAS5 in the esophagus mucosa tissues with statistical significance $(p=0.002)$ (Figure 1A). However, there was no significant correlation between the GAS5 SNP rs55829688 and GAS5 expression (data not shown). Furthermore, the data from the TCGA were applied to evaluate the correlation between GAS5 level and head and neck squamous cell carcinoma. The results demonstrated that a higher GAS5 mRNA level was found in the poor-differentiated cancer cells than the moderate-differentiated cancer cells (Figure 1B). Besides, cancer in the stage IV category and T4 stage also showed a higher GAS5 mRNA level compared to the stage I category and T1 stage ( $p=0.006$ and 0.014 , respectively) (Figure 1C,D). 
Table 4. Clinical statuses and GAS5 rs145204276 genotype frequencies in oral cancer among 598 non-drinkers.

\begin{tabular}{|c|c|c|c|c|}
\hline \multirow[b]{2}{*}{ Variables } & \multicolumn{4}{|c|}{ GAS5 (Rs145204276) } \\
\hline & Ins/Ins $(\%)(n=245)$ & $\begin{array}{l}\text { Ins/Del + Del/Del } \\
(\%)(n=353)\end{array}$ & OR $(95 \%$ CI $)$ & $p$ Value \\
\hline \multicolumn{5}{|l|}{ Clinical Stage } \\
\hline Stage I/II & $133(54.3 \%)$ & $156(44.2 \%)$ & 1.00 & \multirow[t]{2}{*}{$p=0.015^{*}$} \\
\hline Stage III/IV & $112(45.7 \%)$ & $197(55.8 \%)$ & $1.500(1.081-2.081)$ & \\
\hline \multicolumn{5}{|l|}{ Tumor size } \\
\hline$\leq \mathrm{T} 2$ & $139(56.7 \%)$ & $165(46.7 \%)$ & 1.00 & \multirow[t]{2}{*}{$p=0.016^{*}$} \\
\hline$>\mathrm{T} 2$ & $106(43.3 \%)$ & $188(53.3 \%)$ & $1.494(1.076-2.074)$ & \\
\hline \multicolumn{5}{|l|}{$\begin{array}{l}\text { Lymph node } \\
\text { metastasis }\end{array}$} \\
\hline No & $170(69.4 \%)$ & $241(68.3 \%)$ & 1.00 & \multirow[t]{2}{*}{$p=0.772$} \\
\hline Yes & $75(30.6 \%)$ & $112(31.7 \%)$ & $1.053(0.741-1.498)$ & \\
\hline \multicolumn{5}{|l|}{ Distant metastasis } \\
\hline No & $243(99.2 \%)$ & $352(99.7 \%)$ & 1.00 & \multirow[t]{2}{*}{$p=0.364$} \\
\hline Yes & $2(0.8 \%)$ & $1(0.3 \%)$ & $0.345(0.031-3.828)$ & \\
\hline \multicolumn{5}{|l|}{ Cell differentiation } \\
\hline well & $42(17.1 \%)$ & $45(12.7 \%)$ & 1.00 & \multirow[t]{2}{*}{$p=0.134$} \\
\hline Moderate/poor & $203(82.9 \%)$ & $308(87.3 \%)$ & $1.416(0.897-2.235)$ & \\
\hline
\end{tabular}

* denotes significant difference of clinicopathological characteristics between the different GAS5 rs145204276 genotypes.

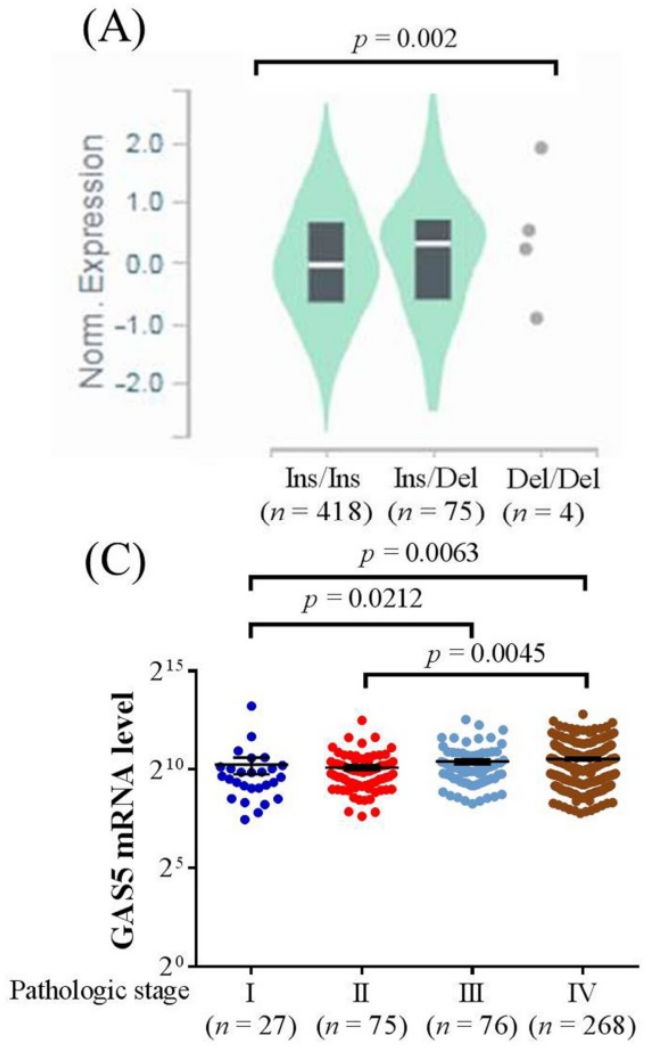

(B)

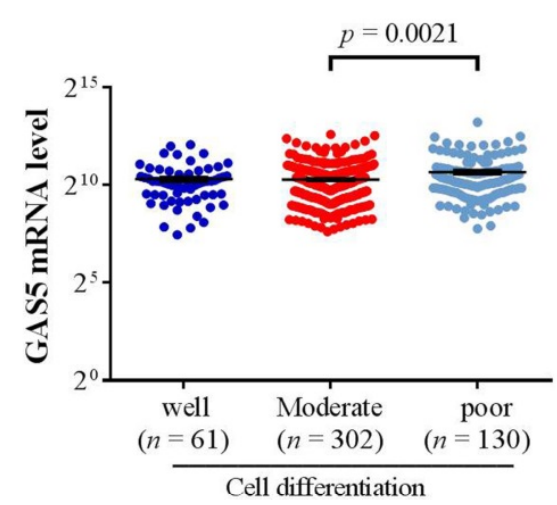

(D)

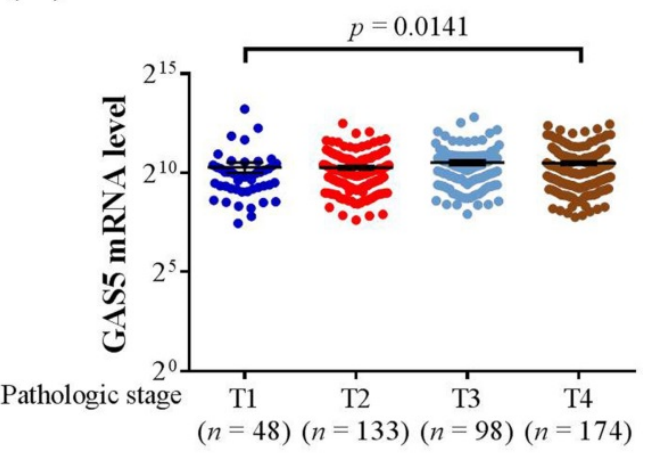

Figure 1. The relationship between growth arrest-specific 5 expression to growth arrest-specific 5 single nucleotide polymorphism rs145204276 and clinical characters of squamous cell carcinoma. (A) The relationship between the presence of growth arrest-specific 5 single nucleotide polymorphism rs145204276 (Ins /Ins, $n=418$; Ins/Del, $n=75$; Del/Del, $n=4$ ) and the growth arrest-specific 5 expression in the esophagus mucosa tissues from Genotype-Tissue Expression database. (B) The correlation between the growth arrest-specific 5 mRNA level and the cell differentiation degree of head and neck squamous cell carcinoma from The Cancer Genome Atlas database. (C) The correlation between the growth arrest-specific 5 mRNA level and the cancer stage of head and neck squamous cell carcinoma from The Cancer Genome Atlas database. (D) The correlation between the growth arrest-specific 5 mRNA level and the tumor size of head and neck squamous cell carcinoma from The Cancer Genome Atlas database. 


\section{Discussion}

In the current study, we found the GAS5 SNP rs145204276 variants (Ins/Del or Del/Del) are related to a poor-differentiation cell character of oral cancer in a male population. Moreover, the same GAS5 SNP is correlated with both the advanced tumor stage and larger tumor size of oral cancer in patients without alcohol consumption. The findings of the current study correspond to the results of a real-world database in which the expression of GAS5 is correlated with the GAS5 SNP rs145204276 variants and severe tumor grading of head and neck squamous cell carcinoma [31].

There are several genetic and environmental confounders that would influence the clinicopathological characteristics of oral cancer [1,3,11,12,33-35]. The pro-inflammatory cytokine interleukin 8 and related SNP is associated with the susceptibility of oral squamous cell carcinoma [36]. In addition, the higher Insulin-like growth factor 2 mRNA-binding protein 2 was found in head and neck squamous cell carcinoma and correlated with higher cancer stage and larger tumor size [17], while the presence of ADAMTS14 SNP rs12774070 was significantly associated with the degree of oral tumor cell differentiation [37]. In addition, gene-environment interactions exist in oral cancer; $C D 44$ polymorphisms and betel quid chewing or tobacco smoking enhance the susceptibility to oral cancer occurrence [38]. Additionally, for the factor that controls cell growth, the MIR4435-2HG caused the upregulation of TGF- $\beta 1$ in oral squamous cell carcinoma [39]. Regarding the aspect of GAS5, it was proven to alter the tumor expression in several types of neoplasms [22,28]. Although the majority of malignancies were suppressed via the higher level of GAS5 [21,23,27], certain cancers benefited from the presence of GAS5 [40]. In previous research, the GAS5 is associated with the progression of glioma [25]. Besides, the GAS5 SNP rs145204276 variant correlated with a poorer five-year survival rate in uterine cervical cancer [26]. According to the above evidences, the GAS5 could lead to tumor development, and SNP rs145204276 might be related to tumor progression [26,40], and the GAS5 can lead to proliferation and invasion of esophageal cancer, which is anatomically similar to the development site of oral cancer [41]. On the other hand, the presence of GAS5 could suppress tumor invasion and proliferation via the miR-21/PTEN axis in the oral squamous cell carcinoma [42]. Moreover, two GAS5 SNPs, which included rs2067079 and rs6790, were associated with a higher possibility of toxic reaction after platinum-based concurrent chemoradiotherapy in patients with nasopharyngeal carcinoma [43]. The above evidence suggests a complex role of GAS5 in the clinical course of oral cancer rather than an absolutely positive or negative role, and such an effect may be altered by specified SNPs and environment factors since both of them can influence the clinical presentation of oral cancer $[37,38,44]$. Consequently, it is possible that the SNP of GAS5 may be associated with the development of oral cancer in a specific gender, which was partially supported by the findings of the current study.

The expression of the GAS5 SNP rs145204276 variant (Ins/Del or Del/Del) is correlated with the poor-differentiation cell type of oral cancer for males in the current study. To our knowledge, this is a preliminary finding that was seldom evaluated elsewhere. A previous study that surveyed a similar ethnicity showed a lower level of GAS5 in the oral squamous cell carcinoma [45]. However, the age and the gender distribution in that study were unknown, so gender may have an interaction effect on the risk factor of cancer [46]. The GAS5 SNP rs145204276 Del variant increases the expression of GAS5 mRNA, which proven in the previous research [47], and the higher concentration of GAS5 may have a prominent effect on the development of oral cancer. Given the fact that the GAS5 has a different effect, either positive or negative, on the tumor progression, invasion and response to treatment in various types of cancers [23,25,40,48], our findings suggest that the presence of the GAS5 SNP rs145204276 variant is a positive factor for severe oral cancer in at least a male population, in contrast to the protective effect for oral cancer in a previous study [42]. The previous study only surveyed the protective effect and related pathway of the general GAS5 phenotype against oral squamous cell carcinoma [42], while certain SNPs may change the effect of GAS5 on oral cancer. Still, the exact mechanism of this phenomenon needs further investigation. 
In the subgroup analysis of the oral cancer population without alcohol drinking, the presence of the GAS5 SNP rs145204276 variant is correlated with the advanced cancer stage and larger tumor size. This is in contrast to the results in the whole oral cancer population in which the above two characters did not show significant differences. The possible explanation is that the alcohol-drinking patients have some genetic variations that influence the susceptibility of tumor progression or GAS5 expression. In a previous study, the adulthood patients that did consume alcohol showed a significant correlation with the polymorphisms in 5HTT, DAT1, DRD4, DRD2 and MAOA [49]. Besides, the deficiency of relaxin-3 was found to increase the alcohol consumption in mice significantly [50]. However, these genes were not tested in the current study; thus, the possible interaction between them and GAS5 SNP needs further research to confirm. On the other hand, the severity of lymph node invasion and distal metastasis did not alter with different GAS5 SNP rs145204276 in both the whole group and subgroup analysis, which may indicate the universally minimal effects of GAS5 SNP in the two clinical characters for oral cancer.

Regarding the real-world cancer database, both the GTEx and TCGA found that a higher expression of GAS5 is associated with the alteration of head and neck tissues [31]. These findings correspond to the results in the current study that the expression of GAS5 SNP may lead to worse clinicopathological characteristics of oral cancer and the adjunct tissue. The GAS5 SNP rs145204276 is related to the higher level of GAS5 expression in the GTEx database, which was also proven in previous study [47]. Moreover, the advanced tumor stage, larger tumor size and poor-differentiation cell status were observed in head and neck squamous cell carcinoma according to the database of TCGA, and the current study also found such a relationship between the GAS5 SNP rs145204276 and the above clinicopathological characteristics. The similar outcomes in our study and the database of TCGA should further strengthen the relationship between GAS5 SNP rs145204276 and the three clinicopathological characteristics of oral cancer, which may be because of a carcinogenic effect of GAS5 SNP rs145204276 [51]. Concerning ethnicity, the population of TCGA comes from all over the world while the study population of the current study is mostly Han Taiwanese. Additionally, the TCGA enrolled both genders while the current study only considered the male population. Such differences may lead to inconsistencies in the significant influence of GAS5 SNP rs145204276 on oral cancers between the current study and the results of TCGA.

Regarding the differences between the study group and the control group in the current study, no difference of GAS5 SNP distribution frequency was found between the two groups for either GAS5 SNP rs145204276 or GAS5 SNP rs55829688. This phenomenon may imply that the GAS5 polymorphism is not a risk factor for oral cancer development in a normal population, but rather a predisposing factor for tumor progression in those with pre-existing oral cancer. Interestingly, the numbers of GAS5 SNP variant types, whether in rs145204276 or rs55829688, were more than the GAS5 SNP wild type in both the study and control groups, which indicates that the etiology needs further study. For the demographic characteristics between the two groups, age was similar between the study and control groups since we chose the patients with similar age as the control group. The ratios of other demographic data, including betel nut chewing, cigarette consumption and alcohol drinking, were all higher in the study group compared to the control group. The reason may be that all three demographic data are prominent risk factors for oral cancer [7].

There are still some limitations in the current study. Firstly, the current study is not a double-blind, randomized control trial; thus, some bias may exist. Second, we did not follow up with the patients with an adequate period to observe the clinical course of patients with different GAS5 polymorphism. In addition, certain diseases such as periodontal disease and chronic Porphyromonas gingivalis are risk factors for the progression of oral cancer [52,53], but we did not enroll them in the multivariable analysis. Finally, oral cancer has several subtypes such as squamous cell carcinomas and mucoepidermoid carcinoma $[54,55]$, but the current study failed to analyze them separately. 


\section{Conclusions}

In conclusion, the presence of the GAS5 SNP rs145204276 variant is correlated with a poor-differentiation cell status in oral cancer in males. Furthermore, a worse tumor stage and tumor size was found in the non-alcohol-drinking group with oral cancer and the GAS5 SNP rs145204276 variant. The above findings might be applied as an evaluation tool for the disease progression of oral cancer in clinical practice for male populations. Further randomized-controlled trials to evaluate whether the GAS5 SNP rs145204276 variant will affect the treatment outcome of oral cancer are mandatory.

Author Contributions: Conceptualization, M.-H.H., H.-J.L., M.-K.C. and S.-F.Y.; formal analysis, C.-W.L., C.-Y.L., S.J.Y. and P.-H.W.; resources, H.-J.L. and M.-K.C.; writing-original draft preparation, M.-H.H., C.-Y.L., M.-K.C. and S.-F.Y.; writing-review and editing, M.-H.H., C.-Y.L., M.-K.C. and S.-F.Y. All authors have read and agreed to the published version of the manuscript.

Funding: This study was also supported by Chung Shan Medical University Hospital (CSH-2012-A-013).

Institutional Review Board Statement: The study was conducted according to the guidelines of the Declaration of Helsinki and approved by the Institutional Review Board of Chung Shan Medical University Hospital (CSMUH No: CS15125).

Informed Consent Statement: Informed consent was obtained from all subjects involved in the study.

Data Availability Statement: The datasets generated for this study are available on request to the corresponding authors or in the TCGA databases.

Acknowledgments: We would like to thank the Human Biobank of Chung Shan Medical University Hospital for providing the biological specimen and related clinical data for our research.

Conflicts of Interest: The authors declare no conflict of interest.

\section{References}

1. Rivera, C. Essentials of oral cancer. Int. J. Clin. Exp. Pathol. 2015, 8, 11884-11894.

2. Valdez, J.A.; Brennan, M.T. Impact of oral cancer on quality of life. Dent. Clin. N. Am. 2018, 62, 143-154. [CrossRef]

3. Montero, P.H.; Patel, S.G. Cancer of the oral cavity. Surg. Oncol. Clin. N. Am. 2015, 24, 491-508. [CrossRef]

4. Yang, S.F.; Hsieh, Y.S.; Tsai, C.H.; Chou, M.Y.; Chang, Y.C. The upregulation of type i plasminogen activator inhibitor in oral submucous fibrosis. Oral Oncol. 2003, 39, 367-372. [CrossRef]

5. Su, S.C.; Chang, L.C.; Huang, H.D.; Peng, C.Y.; Chuang, C.Y.; Chen, Y.T.; Lu, M.Y.; Chiu, Y.W.; Chen, P.Y.; Yang, S.F. Oral microbial dysbiosis and its performance in predicting oral cancer. Carcinogenesis 2021, 42, 127-135. [CrossRef]

6. Yang, S.F.; Huang, H.D.; Fan, W.L.; Jong, Y.J.; Chen, M.K.; Huang, C.N.; Chuang, C.Y.; Kuo, Y.L.; Chung, W.H.; Su, S.C. Compositional and functional variations of oral microbiota associated with the mutational changes in oral cancer. Oral Oncol. 2018, 77, 1-8. [CrossRef] [PubMed]

7. Dhanuthai, K.; Rojanawatsirivej, S.; Thosaporn, W.; Kintarak, S.; Subarnbhesaj, A.; Darling, M.; Kryshtalskyj, E.; Chiang, C.P.; Shin, H.I.; Choi, S.Y.; et al. Oral cancer: A multicenter study. Med. Oral Patol. Oral Cir. Bucal. 2018, 23, e23-e29. [CrossRef]

8. Moro, J.D.S.; Maroneze, M.C.; Ardenghi, T.M.; Barin, L.M.; Danesi, C.C. Oral and oropharyngeal cancer: Epidemiology and survival analysis. Einstein (Sao Paulo) 2018, 16, eAO4248. [CrossRef] [PubMed]

9. Zanoni, D.K.; Montero, P.H.; Migliacci, J.C.; Shah, J.P.; Wong, R.J.; Ganly, I.; Patel, S.G. Survival outcomes after treatment of cancer of the oral cavity (1985-2015). Oral Oncol. 2019, 90, 115-121. [CrossRef] [PubMed]

10. Ghani, W.M.N.; Ramanathan, A.; Prime, S.S.; Yang, Y.H.; Razak, I.A.; Abdul Rahman, Z.A.; Abraham, M.T.; Mustafa, W.M.W.; Tay, K.K.; Kallarakkal, T.G.; et al. Survival of oral cancer patients in different ethnicities. Cancer Invest. 2019, 37, 275-287. [CrossRef]

11. Tahmasebi, E.; Alikhani, M.; Yazdanian, A.; Yazdanian, M.; Tebyanian, H.; Seifalian, A. The current markers of cancer stem cell in oral cancers. Life Sci. 2020, 249, 117483. [CrossRef]

12. Santosh, A.B.; Jones, T.; Harvey, J. A review on oral cancer biomarkers: Understanding the past and learning from the present. J. Cancer Res. Ther. 2016, 12, 486-492. [CrossRef]

13. Khurshid, Z.; Zafar, M.S.; Khan, R.S.; Najeeb, S.; Slowey, P.D.; Rehman, I.U. Role of salivary biomarkers in oral cancer detection. Adv. Clin. Chem. 2018, 86, 23-70.

14. Chung, T.T.; Pan, M.S.; Kuo, C.L.; Wong, R.H.; Lin, C.W.; Chen, M.K.; Yang, S.F. Impact of reck gene polymorphisms and environmental factors on oral cancer susceptibility and clinicopathologic characteristics in taiwan. Carcinogenesis 2011, 32, 1063-1068. [CrossRef]

15. Chen, M.K.; Chiou, H.L.; Su, S.C.; Chung, T.T.; Tseng, H.C.; Tsai, H.T.; Yang, S.F. The association between hypoxia inducible factor-1alpha gene polymorphisms and increased susceptibility to oral cancer. Oral Oncol. 2009, 45, e222-e226. [CrossRef] 
16. Teng, Y.H.; Liu, T.H.; Tseng, H.C.; Chung, T.T.; Yeh, C.M.; Li, Y.C.; Ou, Y.H.; Lin, L.Y.; Tsai, H.T.; Yang, S.F. Contribution of genetic polymorphisms of stromal cell-derived factor-1 and its receptor, cxcr4, to the susceptibility and clinicopathologic development of oral cancer. Head Neck 2009, 31, 1282-1288. [CrossRef]

17. Chou, C.H.; Chang, C.Y.; Lu, H.J.; Hsin, M.C.; Chen, M.K.; Huang, H.C.; Yeh, C.M.; Lin, C.W.; Yang, S.F. Igf2bp2 polymorphisms are associated with clinical characteristics and development of oral cancer. Int. J. Mol. Sci. 2020, 21, 5662. [CrossRef]

18. Chen, M.K.; Yeh, K.T.; Chiou, H.L.; Lin, C.W.; Chung, T.T.; Yang, S.F. Ccr2-64i gene polymorphism increase susceptibility to oral cancer. Oral Oncol. 2011, 47, 577-582. [CrossRef]

19. Su, S.C.; Hsieh, M.J.; Lin, C.W.; Chuang, C.Y.; Liu, Y.F.; Yeh, C.M.; Yang, S.F. Impact of hotair gene polymorphism and environmental risk on oral cancer. J. Dent. Res. 2018, 97, 717-724. [CrossRef]

20. Schneider, C.; King, R.M.; Philipson, L. Genes specifically expressed at growth arrest of mammalian cells. Cell 1988, 54, 787-793. [CrossRef]

21. Ghaforui-Fard, S.; Taheri, M. Growth arrest specific transcript 5 in tumorigenesis process: An update on the expression pattern and genomic variants. Biomed. Pharm. 2019, 112, 108723. [CrossRef]

22. Goustin, A.S.; Thepsuwan, P.; Kosir, M.A.; Lipovich, L. The growth-arrest-specific (gas)-5 long non-coding rna: A fascinating lncrna widely expressed in cancers. Noncoding RNA 2019, 5, 46. [CrossRef]

23. Li, W.; Peng, X.; Wang, Z.; Zhang, H.; Huang, H.; Liu, H.; Cai, L. The long noncoding rna, growth arrest-specific 5, suppresses gastric cancer by downregulating mir-21 expression. Pharmacology 2020, 105, 434-444. [CrossRef]

24. Cheng, Y.; Dai, X.; Yang, T.; Zhang, N.; Liu, Z.; Jiang, Y. Low long noncoding rna growth arrest-specific transcript 5 expression in the exosomes of lung cancer cells promotes tumor angiogenesis. J. Oncol. 2019, 2019, 2476175. [CrossRef]

25. Yuan, J.; Zhang, N.; Zheng, Y.; Chen, Y.D.; Liu, J.; Yang, M. Lncrna gas5 indel genetic polymorphism contributes to glioma risk through interfering binding of transcriptional factor tfap2a. DNA Cell Biol. 2018, 37, 750-757. [CrossRef]

26. Weng, S.L.; Ng, S.C.; Lee, Y.C.; Hsiao, Y.H.; Hsu, C.F.; Yang, S.F.; Wang, P.H. The relationships of genetic polymorphisms of the long noncoding rna growth arrest-specific transcript 5 with uterine cervical cancer. Int. J. Med. Sci. 2020, 17, 1187-1195. [CrossRef]

27. Yu, Y.; Hann, S.S. Novel tumor suppressor lncrna growth arrest-specific 5 (gas5) in human cancer. Onco Targets Ther. 2019, 12, 8421-8436. [CrossRef]

28. Weng, W.C.; Chen, C.J.; Chen, P.N.; Wang, S.S.; Hsieh, M.J.; Yang, S.F. Impact of gene polymorphisms in gas5 on urothelial cell carcinoma development and clinical characteristics. Diagnostics 2020, 10, 260. [CrossRef]

29. Hsiao, P.C.; Chen, M.K.; Su, S.C.; Ueng, K.C.; Chen, Y.C.; Hsieh, Y.H.; Liu, Y.F.; Tsai, H.T.; Yang, S.F. Hypoxia inducible factor-1alpha gene polymorphism g1790a and its interaction with tobacco and alcohol consumptions increase susceptibility to hepatocellular carcinoma. J. Surg. Oncol. 2010, 102, 163-169. [CrossRef]

30. Chen, T.Y.; Li, Y.C.; Liu, Y.F.; Tsai, C.M.; Hsieh, Y.H.; Lin, C.W.; Yang, S.F.; Weng, C.J. Role of mmp14 gene polymorphisms in susceptibility and pathological development to hepatocellular carcinoma. Ann. Surg. Oncol. 2011, 18, 2348-2356. [CrossRef]

31. The genotype-tissue expression (gtex) project. Nat. Genet. 2013, 45, 580-585. [CrossRef] [PubMed]

32. Wang, Z.; Jensen, M.A.; Zenklusen, J.C. A practical guide to the cancer genome atlas (tcga). Methods Mol. Biol. 2016, 1418, 111-141. [PubMed]

33. Sasahira, T.; Kirita, T. Hallmarks of cancer-related newly prognostic factors of oral squamous cell carcinoma. Int. J. Mol. Sci. 2018, 19, 2413. [CrossRef] [PubMed]

34. Kumar, M.; Nanavati, R.; Modi, T.G.; Dobariya, C. Oral cancer: Etiology and risk factors: A review. J. Cancer Res. Ther. 2016, 12, 458-463. [CrossRef] [PubMed]

35. Chen, M.K.; Liu, Y.T.; Lin, J.T.; Lin, C.C.; Chuang, Y.C.; Lo, Y.S.; Hsi, Y.T.; Hsieh, M.J. Pinosylvin reduced migration and invasion of oral cancer carcinoma by regulating matrix metalloproteinase-2 expression and extracellular signal-regulated kinase pathway. Biomed. Pharm. 2019, 117, 109160. [CrossRef]

36. Singh, P.K.; Chandra, G.; Bogra, J.; Gupta, R.; Kumar, V.; Hussain, S.R.; Jain, A.; Mahdi, A.A.; Ahmad, M.K. Association of genetic polymorphism in the interleukin- 8 gene with risk of oral cancer and its correlation with pain. Biochem. Genet. 2016, 54, 95-106. [CrossRef]

37. Su, S.C.; Hsieh, M.J.; Liu, Y.F.; Chou, Y.E.; Lin, C.W.; Yang, S.F. Adamts14 gene polymorphism and environmental risk in the development of oral cancer. PLoS ONE 2016, 11, e0159585. [CrossRef]

38. Chou, Y.E.; Hsieh, M.J.; Hsin, C.H.; Chiang, W.L.; Lai, Y.C.; Lee, Y.H.; Huang, S.C.; Yang, S.F.; Lin, C.W. Cd44 gene polymorphisms and environmental factors on oral cancer susceptibility in taiwan. PLoS ONE 2014, 9, e93692. [CrossRef]

39. Shen, H.; Sun, B.; Yang, Y.; Cai, X.; Bi, L.; Deng, L.; Zhang, L. Mir4435-2hg regulates cancer cell behaviors in oral squamous cell carcinoma cell growth by upregulating tgf- $\beta 1$. Odontology 2020, 108, 553-559. [CrossRef]

40. Yao, T.; Lu, R.; Zhang, J.; Fang, X.; Fan, L.; Huang, C.; Lin, R.; Lin, Z. Growth arrest-specific 5 attenuates cisplatin-induced apoptosis in cervical cancer by regulating stat3 signaling via mir-21. J. Cell Physiol. 2019, 234, 9605-9615. [CrossRef] [PubMed]

41. Li, W.; Zhao, W.; Lu, Z.; Zhang, W.; Yang, X. Long noncoding rna gas5 promotes proliferation, migration, and invasion by regulation of mir-301a in esophageal cancer. Oncol. Res. 2018, 26, 1285-1294. [CrossRef]

42. Zeng, B.; Li, Y.; Jiang, F.; Wei, C.; Chen, G.; Zhang, W.; Zhao, W.; Yu, D. Lncrna gas5 suppresses proliferation, migration, invasion, and epithelial-mesenchymal transition in oral squamous cell carcinoma by regulating the mir-21/pten axis. Exp. Cell Res. 2019, 374, 365-373. [CrossRef] [PubMed] 
43. Guo, Z.; Wang, Y.; Zhao, Y.; Jin, Y.; An, L.; Wu, B.; Liu, Z.; Chen, X.; Zhou, H.; Wang, H.; et al. Genetic polymorphisms of long non-coding rna gas 5 predict platinum-based concurrent chemoradiotherapy response in nasopharyngeal carcinoma patients. Oncotarget 2017, 8, 62286-62297. [CrossRef]

44. Lin, S.H.; Chen, M.K.; Chang, J.H.; Velmurugan, B.K.; Annamanedi, M.; Su, S.C.; Yeh, K.T.; Yang, S.F. Impact of polymorphisms in casein kinase 1 epsilon and environmental factors in oral cancer susceptibility. J. Cancer 2019, 10, 5065-5069. [CrossRef] [PubMed]

45. Yang, M.; Xiong, X.; Chen, L.; Yang, L.; Li, X. Identification and validation long non-coding rnas of oral squamous cell carcinoma by bioinformatics method. Oncotarget 2017, 8, 107469-107476. [CrossRef] [PubMed]

46. Janisch, F.; Shariat, S.F.; Schernhammer, E.; Rink, M.; Fajkovic, H. The interaction of gender and smoking on bladder cancer risks. Curr. Opin. Urol. 2019, 29, 249-255. [CrossRef]

47. Xu, L.; Xia, C.; Xue, B.; Sheng, F.; Xiong, J.; Wang, S. A promoter variant of lncrna gas5 is functionally associated with the development of osteosarcoma. J. Bone Oncol. 2018, 12, 23-26. [CrossRef]

48. Lin, C.Y.; Wang, S.S.; Yang, C.K.; Li, J.R.; Chen, C.S.; Hung, S.C.; Chiu, K.Y.; Cheng, C.L.; Ou, Y.C.; Yang, S.F. Impact of gas5 genetic polymorphism on prostate cancer susceptibility and clinicopathologic characteristics. Int. J. Med. Sci. 2019, 16, 1424-1429. [CrossRef]

49. Guo, G.; Wilhelmsen, K.; Hamilton, N. Gene-lifecourse interaction for alcohol consumption in adolescence and young adulthood: Five monoamine genes. Am. J. Med. Genet. B Neuropsychiatr. Genet. 2007, 144b, 417-423. [CrossRef]

50. Shirahase, T.; Aoki, M.; Watanabe, R.; Watanabe, Y.; Tanaka, M. Increased alcohol consumption in relaxin-3 deficient male mice. Neurosci. Lett. 2016, 612, 155-160. [CrossRef]

51. Lu, S.; Su, Z.; Fu, W.; Cui, Z.; Jiang, X.; Tai, S. Altered expression of long non-coding rna gas5 in digestive tumors. Biosci. Rep. 2019, 39. [CrossRef] [PubMed]

52. Gholizadeh, P.; Eslami, H.; Yousefi, M.; Asgharzadeh, M.; Aghazadeh, M.; Kafil, H.S. Role of oral microbiome on oral cancers, a review. Biomed. Pharm. 2016, 84, 552-558. [CrossRef] [PubMed]

53. Michaud, D.S.; Fu, Z.; Shi, J.; Chung, M. Periodontal disease, tooth loss, and cancer risk. Epidemiol. Rev. 2017, 39, 49-58. [CrossRef]

54. Farr, H.W.; Arthur, K. Epidermoid carcinoma of the mouth and pharynx 1960-1964. J. Laryngol. Otol. 1972, 86, 243-253. [CrossRef] [PubMed]

55. Silverman, S., Jr.; Gorsky, M.; Lozada, F. Oral leukoplakia and malignant transformation. A follow-up study of 257 patients. Cancer 1984, 53, 563-568. 